\title{
PEMANFAATAN PROGRAM "BaTa" PADA PEMBELAJARAN SENI MUSIK UNTUK MENINGKATKAN PEMAHAMAN NOTASI BALOK DAN NOTASI ANGKA SISWA
}

\section{UTILIZATION OF "BaTa" PROGRAM ON THE LEARNING OF MUSIC ART TO IMPROVE UNDERSTANDING OF NOTATION BEAMS AND NOTATION NUMBERS}

\author{
Ardian Arief \\ Pendidikan Guru Sekolah Dasar, Universitas Sarjanawiyata Tamansiswa \\ E-mail: ardian.arief03@ustjogja.ac.id
}

\begin{abstract}
Abstrak : Perkembangan ilmu pengetahuan dan teknologi memberikan kontribusi positif dalam dunia pendidikan, salah satu bentuk kontribusi tersebut ialah produk-produknya. Penggunaan teknologi sudah merupakan bagian dari pembelajaran dan terintegrasi dalam mata pembelajaran di sekolah. Dengan kemudahan yang diberikan oleh teknologi, maka siswa memiliki kesempatan dalam mengembangkan pembelajaran dengan cara yang lebih menarik dan bervariasi sesuai dengan gaya belajar masing-masing. Seni musik merupakan salah satu bidang keilmuan yang muncul di sekolah, dan salah satu materi yang diajarkan adalah penguasaan notasi balok dan angka. Kehadiran program "BaTa" (Balok to Angka) sebagai salah satu buah teknolgi dapat dimanfaatkan dalam membantu siswa dalam memahami notasi balok dan angka sebagai bahasa musik. Program BaTa merupakan program untuk menterjemahkan bentuk notasi, sehingga siswa memiliki pengalaman pribadi dalam mengenal bentuk, tempat, dan simbol notasi.
\end{abstract}

Kata Kunci: Program BaTa, Pembelajaran Seni Musik, Pemahaman Notasi Balok dan Notasi Angka

Abstract: Developments in science and technology make a positive contribution in the world of education, one of these contributions is its products. The use of technology has been an integrated part of learning and teaching in schools in the eye. With the convenience provided by the technology, the students have the opportunity to develop learning in a more interesting and varied according to the learning style of each. Art music is one of the scientific fields that appear in school, and one of the material being taught is the mastery of notation and numbers. The presence of the program "brick" (Beams to figure) as one of the technologically fruit can be used in assisting students in understanding the notation and numbers as the language of music. Brick program is a program to translate the form of notation, so that students have personal experience in a familiar form, place, and symbols notation.

Keywords: Brick Program, Learning Of Music Art, Understanding Of Notation beams and notation numbers

\section{PENDAHULUAN}

Mata pelajaran Seni Musik merupakan salah satu mata pelajaran di sekolah, mulai dari dasar sampai ke tingkat atas. Salah satu materi dalam mata pelajaran seni musik adalah membaca notasi musik. Notasi musik merupakan bahasa dalam sebuah karya musik. Notasi digambarkan dengan simbol-simbol yang kemudian diartikan atau dinyatakan lewat sebuah permainan pada instrumen musik.
Notasi memiliki dua bentuk, yaitu notasi angka dan notasi balok. Bentuk notasi balok merupakan simbol yang sudah menjadi bahasa yang umum dan universal di dunia musik dan juga menjadi bahan ajar dalam pelajaran musik di sekolah. Menurut Banoe (2003:299), notasi balok adalah tulisan musik dengan menggunakan lima garis datar guna menunjukan tinggi rendah suatu nada, dan notasi angka adalah tulisan musik dengan menggunakan angka sebagai satuan ukuran jenjang nada. Hal ini diperkuat 
dengan pendapat Mudjilah (1998:4) yang menyatakan bahwa notasi musik menggambarkan besarnya waktu dalam arah horizontal, dan tinggi-rendah nada-nada dalam arah vertical. Berikut ini adalah gambar.1 yang menjelaskan bagian-bagian notasi balok.

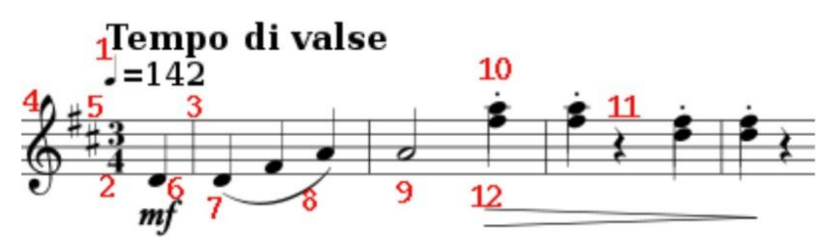

Gambar 1. Bagian notasi balok

1. Di sebelah kiri atas pada awal lagu biasanya ditempatkan petunjuk tempo (yaitu kecepatan lagu), seringkali dalam bahasa Italia, yang di sini menunjukkan "tempo waltz". Selain itu juga terdapat penanda metronom dalam satuan BPM (beats per minute), di sini 142 ketukan per menit.

2. Tanda birama menunjukkan ritme lagu. Angka di bagian atas tanda birama menunjukkan jumlah ketukan per birama, sedangkan angka di bawah menunjukkan nilai not per ketukan. Tanda birama $3 / 4$ di sini menunjukkan bahwa terdapat tiga ketukan dalam birama, satu ketukan kuat diikuti dua ketukan lemah, dan masing-masing ketukan bernilai not seperempat.

3. Garis birama merupakan pemisah antarbirama.

4. Pada bagian awal paranada terdapat kunci $G$ yang menandakan bahwa garis kedua dari bawah melambangkan nada $g^{1}$ (berfrekuensi sekitar $418 \underline{\mathrm{Hz}}$.

5. Tanda mula utama yang di sini terdiri dari dua tanda mula kres pada garis nada $\mathrm{c}$ dan $\mathrm{f}$ menunjukkan bahwa kedua nada tersebut dinaikkan setengah nada dalam semua oktaf (dimainkan sebagai nada cis dan fis) serta menunjukkan bahwa karya musik bersangkutan bertangga nada $\mathrm{D}$ mayor atau $\mathrm{B}$ minor.

6. Not pertama adalah not seperempat dengan nada $\mathrm{d}^{1}$, dengan dinamika (nyaring lembutnya suara) $m f$ (bahasa Italia, mezzo forte: sedikit nyaring). Dapat dilihat bahwa not tersebut langsung diikuti garis birama walaupun tiga ketuk dalam birama tersebut belum selesai. Dengan demikian, karya ini dimulai bukan dengan ketukan pertama bertekanan, melainkan dengan ketukan ketiga lemah dalam suatu birama pembuka (anacrusis).

7. Not kedua juga merupakan not seperempat dan bernada $\mathrm{d}^{1}$ yang jatuh pada ketukan pertama dalam birama berikutnya.

8. Tanda legato menghubungkan not $\mathrm{d}^{1}$ tersebut dengan not fis ${ }^{1}$ dan $a^{1}$, menandakan bahwa ketiga not tersebut harus dimainkan secara legato (sambung-menyambung).

9. Pada birama berikutnya terdapat not setengah bernada $a^{1}$ berdurasi dua ketukan.

10. Berikutnya terdapat not seperempat dengan dua kepala not pada posisi nada fis ${ }^{2}$ dan $\mathrm{a}^{2}$, menandakan bahwa kedua nada tersebut harus dimainkan bersamaan. Di atas not tersebut terdapat tanda staccato, menandakan bahwa not tersebut harus dimainkan secara staccato (terpisah nyata dari not sebelum dan sesudahnya).

11. Tanda diam seperempat menandakan bahwa tidak ada nada yang dimainkan selama (dalam hal ini) satu ketukan.

12. Di bawah tiga birama terakhir terdapat tanda decrescendo, menandakan bahwa pada ketiga birama tersebut terdapat perubahan dinamika, yaitu dimainkan makin melembut (dapat juga ditulis decresc. atau dim., diminuendo).

Sedangkan berikut adalah bagian-bagian dari notasi angka.

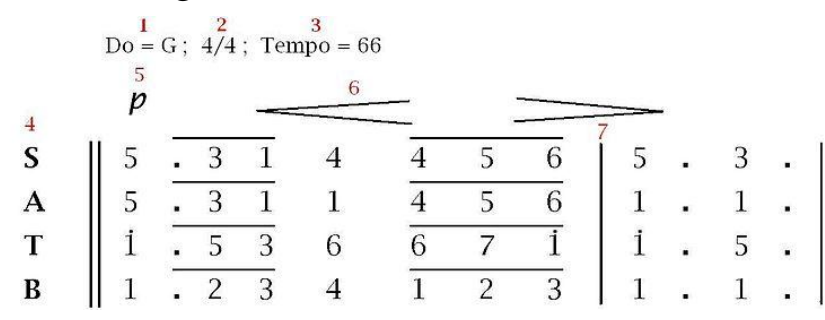

Gambar 2. Bagian notasi angka

1. Do $=\mathrm{G}$ menunjukkan nada dasar lagu tersebut.

2. 4/4 menunjukkan Tanda birama yang menunjukkan ritme lagu. Angka di bagian atas tanda birama menunjukkan jumlah ketukan per birama, sedangkan angka di bawah menunjukkan nilai not per ketukan. Tanda birama 4/4 di sini menunjukkan bahwa terdapat empat ketukan dalam birama, satu ketukan kuat diikuti tiga ketukan lemah, dan masing-masing ketukan bernilai not seperempat 
3. Tempo $=66$ menunjukkan tempo lagu, artinya dalam satu menit ada 66 ketuk.

4. SATB menunjukkan tipe suara yang menyanyikan baris tersebut.

5. P berarti 'piano' yang berarti lembut, artinya lagi ini dengan dinamika yang lembut.

6. Tanda Crescendo yang dilanjutkan dengan tanda decrescendo, menunjukkan ada perubahan dinamika, yakni mengeras, kemudian melembut lagi.

7. Garis birama yang merupakan pemisah antarbirama.

Bentuk notasi angka belum menjadi bahasa yang umum karena tidak semua arranger atau komposer menggunakan notasi angka dalam penulisan karya musiknya. Dari observasi yang dilakukan pada mahasiswa Pendidikan Guru Sekolah Dasar (PGSD) Univeritas Sarjanawiyata Tamansiwa (UST) (observasi 21 April 2015), mereka yang sudah pernah mendapatkan pelajaran musik saat mulai dari Sekolah Dasar (SD) sampai Sekolah Menengah Atas (SMA) tidak begitu ditekankan pada penguasaan notasi, walaupun ada hanya seBaTas pemahaman singkat notasi angka. Sehingga pada saat mengikuti mata kuliah Seni Musik mengalami kesulitan dalam membaca karya musik yang ditulis dalam notasi.

Untuk itu pentingnya bagi siswa dalam menguasai notasi balok dan notasi angka sebagai teori dasar musik pada proses belajar mengajar di sekolah. Aspek teknologi sangat mendukung dan menunjang tercapainya tujuan pendidikan. Bagi pelajaran seni musik, teknologi dapat digunakan untuk membangun dan mengasah musikalitas, rasa, dan teori musik itu sendiri.

Penelitian yang dilakukan oleh Alamveta (2007) dapat diketahui bahwa latar belakang kemunculan program musik adalah buku-buku khusus untuk penulisan notasi cenderung susah didapat dan mahal, oleh karena itu maka berkembanglah program-program komputer musik dari yang free (gratisan) sampai yang berbayar. Banyak program di pasaran yang sudah menawarkan kemudahan dalam bermusik, namun dalam konteks pembelajaran musik dasar belum begitu banyak.

Beberapa progam yang umum digunakan dalam menulis notasi adalah Encore, Finale, Music Scoring, Sibelius dan lainnya. Namun program-program tersebut hanya seBaTas penulisan pada bentuk notasi balok saja, dan masih belum menyertakan fitur transcript notasi angka. Program BaTa merupakan program yang dapat dijalankan di sistem operasi Windows, sehingga diharapkan dengan sistem operasi ini siswa dapat dengan mudah menggunakannya karena pada umumnya kompter di Indonesia berbasis sistem operasi Windows. Fitur yang yang dimiliki program BaTa adalah mampu mentranskrip notasi balok ke notasi angka, dan memiliki banyak fitur suara dan dapat mencetak file. Menurut Badudu (2003: 351) transkrip adalah salinan, dan transkripsi berarti penyalinan teks dengan huruf lain untuk menunjukkan lafal fonem bahasa yang bersangkutan. Pendapat lain mengatakan bahwa transkrip memiliki arti yang sama dengan transkripsi yang berarti menyalin dengan menulis, menyebrang dan melintas (Martinus, 2001: 638).

Artikel ini bertujuan untuk memberikan informasi bahwa program BaTa dapat mempermudah atau membantu guru dan siswa yang mengalami kesulitan dalam membaca notasi balok dan angka, walaupun pada dasarnya membaca notasi balok lebih diutamakan dalam teori musik. Program BaTa merupakan program yang free atau gratis, sehingga diharapkan mampu membantu guru dan siswa dalam mempelajari notasi musik.

\section{PEMBAHASAN}

\section{A. Mengenal Program BaTa}

Program BaTa adalah program yang dikembangkan oleh pada sistem Windows. Program ini dikembangkan pada tahun 2008 oleh Ardian Arief, seorang mahasiswa Pendidikan Seni Musik Universitas Negeri Yogyakarta. Versi yang telah dikembangkan adalah Bata Versi V.1.0. Berikut gambar.3 tentang informasi versi BaTa.

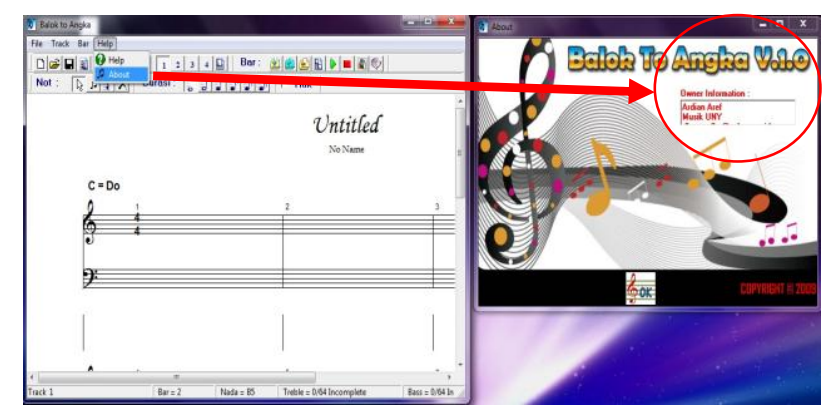

Gambar 3. Versi BaTa 
Tampilan utama program BaTA terilhat sederhana dan simpel agar pengguna mudah dalam mengoperasikan. Pada tampilan utama muncul beberapa menu utama, menu notasi, garis paranada, dan beberapa tombol kontrol audio. Berikut gambar. 4 tentang bentuk tampilan utama program BaTa.

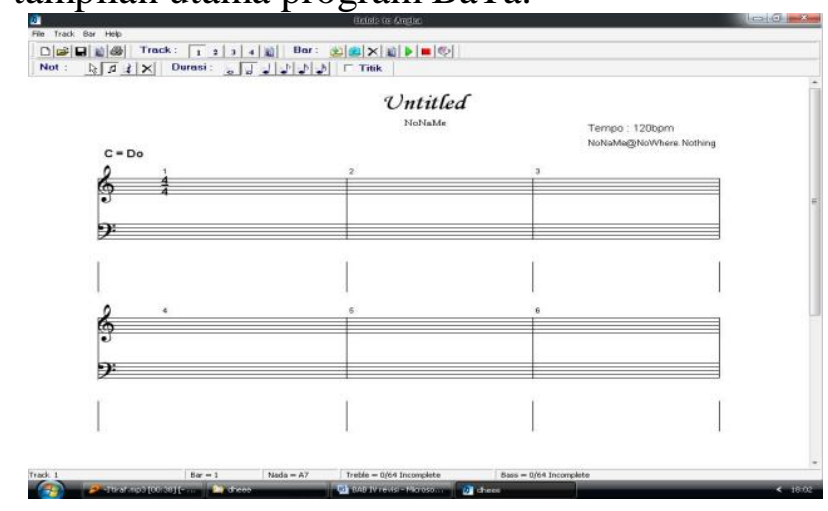

Gambar 5: Bentuk tampilan utama adalah :

Penjelasan fitur-fitur pada gambar. 5

1. Tool File, yang terdiri dari New untuk membuat file baru, Open untuk membuka file dan Save untuk menyimpan file.

2. Tool Track, yang terdiri dari Properti yang berfungsi mengatur track yang dipakai. Pengaturannya yaitu memilih suara pada setiap track dengan suara yang disediakan

3. Tool Bar, yang terdiri dari Add Bar, Insert Bar, Delete Bar, dan Properti untuk mengatur jenis garis dan tanda sukat.

4. Tool Help, yang terdiri dari Help dan About.

Beberapa fitur yang muncul pada bagian toolbar adalah:

1. Fitur cetak, untuk mencetak data yang dikerjakan. Pada tampilan ini akan ditampilkan pekerjaan yang akan dicetak dan jumlah halaman yang akan dicetak.

2. Fitur Properti, untuk mengatur properti lagu seperti judul, pengarang, catatan, tempo dan tonika.

3. Fitur Not, untuk memilih bentuk atau mode not, diantaranya anak panah, not untuk menulis notasi, istirahat untuk pilihan tanda istirahat, dan hapus untuk menghapus data
4. Fitur Durasi, untuk memilih durasi notasi yang akan dipakai.

5. Fitur Track, menyediakan empat sheet suara dengan kemampuan berbeda-beda suara sesuai pilihan yang diilih pada icon properti track.

6. Pada icon properti disediakan enam belas jenis suara primer dan beberapa sub primer, yang bisa di pakai disetiap track yang dipilih. Fungsi ini juga yang terdapat pada tool track.

7. Fitur Play dan Stop, berfungsi untuk memainkan dan menghentikan lagu yang di perdengarkan.

Fungsi dari beberapa sub menu tersebut dapat dijelaskan pada tabel di bawah ini:

Table 1: Fungsi menu pada toolbar perangkat lunak

\begin{tabular}{|l|l|}
\hline Menu & \multicolumn{1}{|c|}{ Fungsi } \\
\hline 1. New & Membuat lembar \\
2. Open & Merja baru file \\
3. Save & yang tersimpan \\
4. Save As & Menyimpan file \\
5. Exit & yang dikerjkan \\
6. add bar & Menyimpan file \\
7. insert bar & dengan nama \\
8. delete bar & yang berbeda dari \\
9. property & Keluar \\
10. Help & program \\
11. About & bar menambah \\
& untuk \\
& menyisipkan bar \\
& untuk menghapus \\
bar \\
untuk mengatur \\
& jenis garis bar \\
dan waktu tanda \\
sukat \\
petunjuk \\
penggunaan \\
berisikan data \\
pemilik \\
Perangkat lunak \\
\hline
\end{tabular}

Beberapa keunggulan program ini antara lain adalah :

1. bisa membuat sheet musik dari susunan not balok pada bar notasi yang terbagi menjadi 4 track suara. 
2. secara otomatis mengkonversi not balok pada sheet menjadi not angka.

3. mampu memainkan nada dari not yang sudah disusun pada track.

4. dapat menyimpan sheet musik ke dalam sebuah file untuk digunakan kemudian.

5. mencetak sheet musik yang dikerjakan.

Perangkat lunak ini dapat beroperasi pada sistem Windows, jadi para pengguna dapat dengan mudah menjalankan program ini di PC masing-masing, karena pada umumnya komputer yang berkembang menggunakan menggunakan sistem operasi Windows. Perangkat lunak ini terkumpul sebuah folder yang didalamya terdiri dari beberapa file yaitu satu file Exe atau installter program, file Font dan file Help.

Untuk dapat menggunakan perangkat lunak ini, pengguna dapat membuka folder BaTa dan mengklik icon BaTa.Exe, dan kemudian program dengan otomatis dapat berjalan. Perangkat lunak ini bersifat portable, masksudnya dari sebuah icon installter denga tipe exe, program langsung dapat dijalankan tanpa harus menginstal terlebih dahulu. Setelah program dijalankan, maka muncul tampilan utama di layar seperti pada gambar. 5 .

Setelah tampilan utama muncul, maka program dapat digunakan dengan mengarahkan kursor ke menu Not, dengan beberapa pilihan mode yaitu mode kursor, mode not, mode rest, dan mode delete. Menu ini digunakan untuk memasukkan notasi dan mengedit notasi.

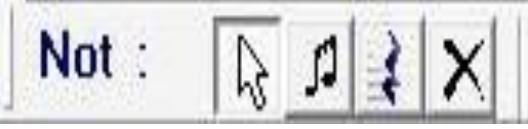

\section{Gambar 6. Menu not}

Berikut ini merupakan sebuah contoh bagaimana menggunakan perangkat lunak BaTa untuk menuliskan notasi :

1. Klik icon biru untuk menjalankan aplikasi,

2. Setelah menjalan aplikasi maka akan muncul tampilan utama di layar monitor.

3. Untuk menentukan tonika, menukis judul, pengarang dan keterangan lain, dapat membuka icon properti seperti.

4. Pengaturan telah ditentukan oleh pengguna, maka setelah itu bisa diteruskan dengan menulis notasi. Untuk menulis notasi balok, dapat menekan icon pada menu not di icon nada. Dan dalam fungsi lain seperti memberi tanda istirahat dan meghapus not juga terdapat pada menu not. Not diletakkan pada garis paranada yang disediakan, nada bisa diletakkan pada sheet satu, sheet dua, sheet tiga atau empat, tergantung kebutuhan pemakai dalam menuliskan lagu.

5. Untuk mengatur suara per Track, pemakai dapat memasuki menu pada toollbar track atau menekan icon track untuk menampilkan menu track properti. Untuk track yang ingin tidak dibunyikan, dapat mengaktifkan fungsi Mute. Setelah semua diatur, maka ketika dimainkan akan mengeluarkan suara yang berbeda tergantung kebutuhan pengguna.

6. Setelah notasi ditulis, maka bisa dimainkan dengan menekan icon play dan untuk menghentikannya dengan menekan tombol stop. Sedangkan untuk menambah, menyisipkan sarta menghapus bar, bisa manggunakan icon pada menu bar.

7. Setelah semua selesai, maka data dapat disimpan dengan membuka menu file dan memakai fungsi Save dan Save As, serta untuk membuka file yang tersimpan, dapat menggukan fungsi open. Data lagu yang disimpan memiliki tipe "nama file". NOT

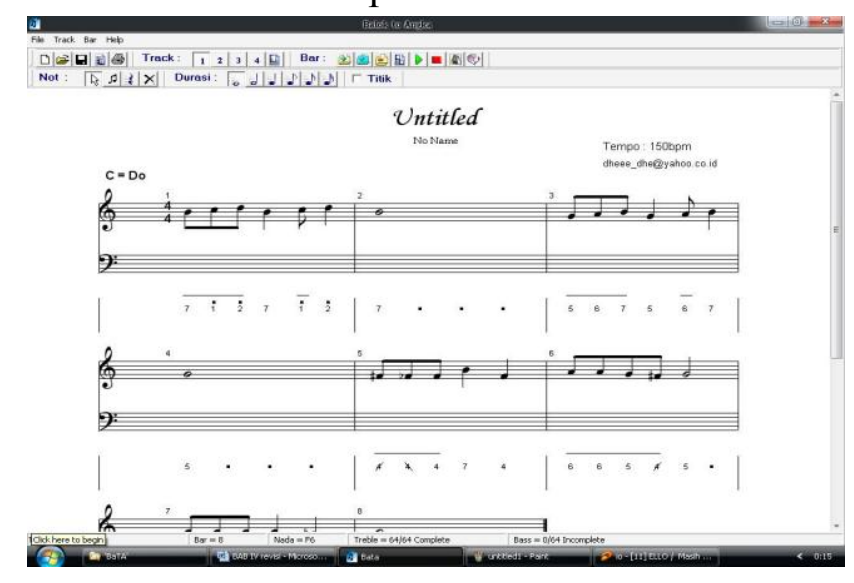

Gambar 7: Tampilan masukan notasi 


\section{B. Program BaTa untuk meningkatkan pemahaman notasi balok dan notasi angka}

Pada gambar.7 terlihat bahwa paranada terisi dengan dua bentuk notasi yaitu notasi balok dibagian atas dan notasi angka dibagian bawah. Sehingga ketika siswa memasukkan data notasi balok yang ingin di terjemahkan atau transkripkan kebentuk notasi angka akan muncul secara otomatis di bawah paranada.

Pada proses ini, siswa dapat menghafalkan bentuk, posisi, harga, dan ketukan notasi pada sistem notasi balok sekaligus mengetahui kedudukan, angka, dan terjemahan dalam bentuk notasi angka. Ketika notasi terbentuk dalam dua bentuk, maka siswa bisa membandingkan bentuk dan memahami cara membaca notasi angka ang kemudian diaplikasikan kebentuk notasi balok.

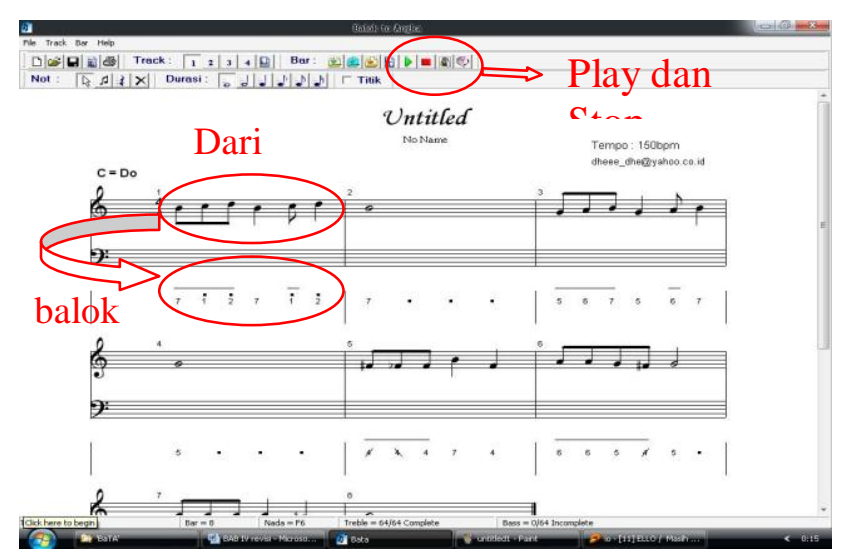

\section{Gambar 8. Bentuk pemanfaatan program BaTa}

Pada saat notasi telah dimasukkan, maka siswa dapat mendengar notasi tersebut sekaligus memamahi tinggi rendah nada, untuk kemudian dapat dibunyikan kembali oleh siswa tersebut dengan suara masing-masing sesuai dengan nada yang ada.

Sebagai latihan, salah satu notasi bisa ditulis dan siswa mengisi transkrip bentuk notasi lain. Latihan juga bisa diberikan dalam bentuk cetak maupun langsung menggunakan program BaTa. Bentuk latihan lain ialah dengan mengulang bunyi nada yang sudah dimasukkan, baik dalam bentuk notasi balok maupun notasi angka.

\section{Simpulan}

Penelitian ini telah dapat menghasilkan sebuah produk berupa perangkat lunak yang diberi nama BaTa, yang berarti Balok To Angka. Pengerjaan perangkat lunak ini menggunakan bantuan komputer dan program Borland Delphi 7. Perangkat lunak yang dihasilkan memiliki kemampuan antara lain; (1)bisa membuat sheet musik dari susunan not balok pada bar notasi yang terbagi menjadi 4 track suara; (2)secara otomatis mengkonversi not balok pada sheet menjadi not angka; (3)mampu memainkan nada dari not yang sudah disusun pada track; (4)dapat menyimpan sheet musik ke dalam sebuah file untuk digunakan kemudian; (5)mencetak sheet musik.

Dengan teknologi yang semakin maju, diharapkan kepada guru-guru disekolah lebih mengembangkan metode pengajaran dengan menggunakan teknologi. Diharapkan dengan produk ini mampu memacu semangat belajar dan kreativitas siswa bidang seni musik di sekolah. Diharapkan dengan produk yang dihasilkan dari penelitian ini, bisa dijadikan kontribusi yang positif bagi dunia pendidikan Indonesia.

\section{Daftar Pustaka}

\section{Badudu, JS. 2003. Kamus Kata- Kata Serapan Asing Dalam Bahasa Indonesia. Jakarta: Penerbit Buku Kompas.}

Banoe, Pono. 2003. Kamus Musik. Yogyakarta: Kanisius.

Mudjilah, Sri Hanna. 1998. Teori Musik Dasar. Yogyakarta: Institut Keguruan Ilmu Pendidikan Yogyakarta

Prier, Edmund-Karl. 1991. Sejarah Musik Jilid 1. Yogyakarta: Pusat Musik Liturgi.

Supriadi, Muhammad. 2005. Pemrograman IC PPI 8255 Menggunakan Delphi. Yogyakarta: Andi.

Syafiq, Muhammad. 2003. Ensiklopedi Musik. Yogyakarta: Adicita

\section{Situs internet:}

Ucup. 2005. Asal-Usul Notasi Musik.. http://www.

Freelists.org/archives/nasional. 
Diakses tanggal 18 Januari 2009, pukul 21.30 WIB

Tandrio, Rizal A. 2002. Asal Muasal Not Angka. http://groups.yahoo.com. Diakses tanggal 15 Januari 2009 pukul 18.35 WIB.

\section{Karya ilmiah :}

Poernomo, Samuel Marco (2007). Perancangan dan Pembuatan Editor Untuk Menulis Not. Skripsi. Surabaya: Fakultas Teknologi Industri, Universitas Kristen Petra
Alamveta, Richie (2007). Perancangan dan Pembuatan aplikasi Penulisan Notasi Balok Dari file MIDI. Skripsi. Surabaya: Fakultas Teknologi Industri, Universitas Kristen Petra

Sartika, Dewi (2006). Perancangan dan Pembuatan Perangkat lunak Aplikasi Pembelajaran Ikatan Kimia Hidrokarbon Untuk SMA Kelas I. Skripsi. Surabaya: Fakultas Teknologi Industri, Universitas Kristen Petra 